\title{
MONITORING AND ASSESSMENT OF ECOLOGICAL CHANGE IN COASTAL CITIES BASED ON RSEI
}

\author{
Liu Xiaoying ${ }^{1}$, Zhang Xinxin ${ }^{1 *}$, He Yuanrong ${ }^{1}$, Luan Haijun $^{1}$ \\ ${ }^{1}$ College of Computer and Information Engineering, XiamenUniversity of Technology, Xiamen 361024, China - \\ 3097815294@qq.com, Zhangxinxin@xmut.edu.cn, 2012112001@xmut.edu.cn,540397310@qq.com
}

KEY WORDS: RSEI, Ecological quality evaluation, Remote sensing, Landsat 8, Sentinel-2A

\begin{abstract}
:
With the speeding up of urbanization process, ecological problems, such as unsustainable land use and environmental pollution,have emerged one after another in cites. Nowadays, green development and ecological priority are the important concepts and trends of the current new urban planning in China. In this study, Pingtan County, a coastal city in Fujian Province, China, was taken as the research area. Based on two Landsat 8 remote sensing images $(2016,2017)$, and two Sentinel-2A remote sensing images (2016, 2017), we first adopt the modified normalized water body index (MNDWI) to mask the water body. Four indicators, including greenness, humidity, dryness and heat were extracted to synthesize the remote sensing ecological index (RSEI), which were obtained by principal component analysis method. Based on the RSEI values acquired from Landsat 8 and Sentinel-2A images, the ecological environment change trend in Pingtan County was evaluated.The experimental results show that: 1) The RSEI indicators based on Landsat 8 and sentinel data all show a downward trend, but due to due to the influence of image spatial resolution and PCA weighting coefficient, the RSEI index has different degrees of decline. 2) The main reason for the decline in RSEI is the increase in NDSI indicators. Compared with July 2016, the bare ground increased in April 2017. Although the NDVI has increased, the overall trend is still declining. Therefore, it is necessary to ecologically return farmland and improve vegetation coverage in the future development process. 3) In recent years, the ecological quality of new construction land near drinking water sources has declined, so it is necessary to strengthen monitoring of changes in the region.
\end{abstract}

\section{INTRODUCTION}

${ }^{1}$ With the rise of spatial information technology, remote sensing has incomparable advantages compared with traditional survey methods. It can provide abundant information of resources and environment quickly and accurately. It can provide real-time and dynamic spatial-temporal change information for ecological environment regulation and control by organic combination with geographic information system (Li H Y, 2006). Remote sensing techniques have been widely used in ecological and environmental investigations (Kennedy et al., 2014).At present, there are many models for monitoring and evaluating the ecological environment. For example, (Ochoa-Gaona S et al., 2010) established a model of the ecological status of tropical forests, aggregated two or more indicators into a simple index, which evaluates the ecological status of forests according to the ratio of 0 (worst condition) to 1 (best condition). (Yuan, F et al., 2007) proposed that ISA can be used to better study urban heat island effect by studying the relationship between land surface temperature (LST), impervious surface area percentage (ISA) and surface vegetation index (NDVI). The Remote sensing derived land surface temperature (LST) has also been frequently used to characterize urban heat island (UHI) (Nichol, 2009; Xu H Q et al., 2017). However, most of the above models use a single index to evaluate the urban ecological environment and explain a single feature, which cannot carry out the overall regional

* Corresponding author.

E-mail address: Zhangxinxin@xmut.edu.cn (Zhang Xinxin) assessment.

Comprehensive ecological indicators should be used in regional ecological assessment. For example, the Eco-environmental Status Index (EI) (Wan B T et al., 2009), which was launched by China's General Administration of Environment, integrated biological abundance index, vegetation cover index, water network density index, land degradation index and environmental quality index to evaluate regional ecological environment quality. The evaluation index of urban ecological environment quality is established based on expert experience weighting method. However, the evaluation factors of EI model are complex, and the basic data needed are often difficult to obtain, thus affecting the popularization and use of these methods. In addition, some methods reduce the credibility of evaluation results because index weight mainly depends on subjective artificial setting.To solve these problems, (Xu H Q et al.,2013) proposed a new ecological evaluation index based on remote sensing information, remote sensing ecological index (RSEI). The biggest advantage of this method is that the weight of each indicator is not artificially determined, but principal component analysis (PCA) is used to objectively assign the weight of each ecological factor, thus improving the subjective bias method of determining the weight by experts in EI. The data obtained from remote sensing images can extract a variety of factors for evaluating environmental quality. Combined with geo-assistant information, various ecological models can be established. It is an effective and simple method for evaluating regional environmental quality and can provide technical support for decision-making of government departments. 
urban ecosystem monitoring and evaluation. However, the existing ecological indicators are seldom used in urban and rural planning practice (Lakes and Kim, 2012). At the same time, most scholars are only based on Landsat satellite imagery for research, and the new Sentinel-2A remote sensing data is still relatively few for comprehensive ecological assessment. Therefore, this paper aims to (1) Based on Landsat 8 (2016, 2017) and Sentinel-2A (2016,2017), their RSEI values and their visualization results were compared, (2) Based on the RSEI results, we track the spatial and temporal variation of ecological environment quality of Pingtan in the past two years, and their causes were analyze, and(3) Demonstrate how to convert ecological indicators into direct application of urban green development by using RSEI model. The results of the study will help to improve the comprehensive utilization efficiency of different remote sensing data and provide a scientific basis for the local government to develop a green ecological urban development plan.

\section{METHODS}

\subsection{Study area}

Pingtan County is located in the eastern part of Fujian Province and the northern part of Taiwan Strait, is the nearest Island County in mainland China to Taiwan. It is composed of 126 islands, mainly Haitan Island (also known as Pingtan Island, 25 degrees $166^{\prime}-25$ degrees $44^{\prime} \mathrm{N}, 119$ degrees $32^{\prime}-120$ degrees $10^{\prime} \mathrm{E}$ ). Haitan Island is the largest island in Fujian Province and the fifth largest island in China. In this study, Haitan Island is taken as the research area (Figure1). The land area is $267 \mathrm{~km}^{2}$, accounting for $72 \%$ of the total area of Pingtan County, and the reclaimed sea area is $26.61 \mathrm{~km}^{2}$. The island is low and flat, with a slightly higher central part. Its topography is dominated by marine plains. There are isolated hills in the north and south, and its coastline is tortuous. The area belongs to warm, hot and humidclimate and has an average annual precipitation of $1196.2 \mathrm{~mm}$, an annual average temperature of $19.5^{\circ} \mathrm{C}$. The average temperature of the coldest day is $10.2^{\circ} \mathrm{C}$, and the average temperature of the hottest day is $27.9^{\circ} \mathrm{C}$.

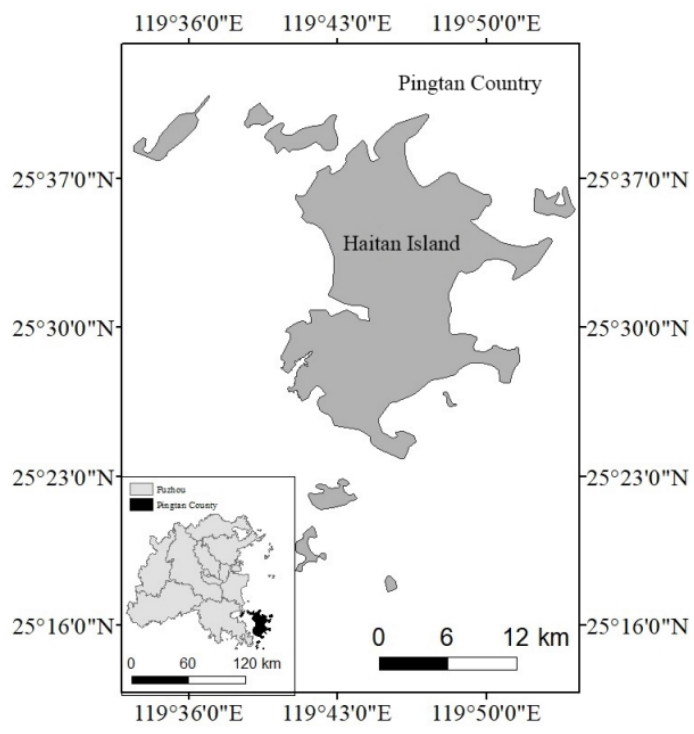

Figure 1. Location of Pingtan County

\subsection{Remote sensing data and image preprocessing}

The twoSentinel-2A remote sensing images acquired on June 23, 2016 and April 29, 2017 from the website of the European Space Agency (https://scihub.copernicus.eu/dhus) and the two Landsat 8 OLI remote sensing images acquired onJuly 20, 2016 and April 2, 2017 from the website of the United States Geological Survey (https://earthexplorer.usgs.gov/). Combination of the data from these two sun-synchronous polar orbiting systems provides a global median average revisit interval of 4.6days ( $\mathrm{Li}$ and Roy, 2017). Sentinel-2A series plans to launch two satellites and build a Double-satellite earth observation platform. It is mainly used for monitoring global ecological environment. It has the characteristics of high spatial resolution of $10 \mathrm{~m}$, abundant band information and free sharing. Therefore, it is of great significance for the further research and application of the satellite.Landsat 8 image was used complementary to the Sentinel-2A image because it lacks thermal infrared band. At the same time, in order to ensure the comparability of the results, the images with the same seasonal phase and type are strictly selected as remote sensing data sources, so that the vegetation in different years has similar growth status. Due to no qualified Landsat 8 imagery available for the date close to that of the Sentinel 2A image, in this paper, Sentinel-2A and Landsat 8 images with the closest date in the same year are selected. By comparing the temperature and rainfall on that day, it is found that the weather conditions are quite similar between the overpass times of the two satellites (Table 1). Finally, the Landsat8 (TIRS) image of July 20, 2016 was selected to supplement Sentinel-2A image of June 23, 2016 and the Landsat8 (TIRS) image of April 2, 2017 was selected to supplementSentinel-2A image of April 29, 2017.

\begin{tabular}{ccccc}
\hline Satellite & $\begin{array}{c}\text { Date and } \\
\text { local time }\end{array}$ & $\begin{array}{c}\text { Wind } \\
\text { speed } \\
(\mathrm{m} / \mathrm{h})\end{array}$ & $\begin{array}{c}\text { Air } \\
\text { temperature } \\
\left({ }^{\circ} \mathrm{C}\right)\end{array}$ & $\begin{array}{c}\text { Precipitation } \\
(\mathrm{mm})\end{array}$ \\
\hline $\begin{array}{c}\text { Sentinel } \\
-2 \mathrm{~A}\end{array}$ & 20160720 & 3 & 32 & 0 \\
$\begin{array}{c}02: 26: 34 \\
\text { Landsat } \\
8\end{array}$ & 20160623 & 3 & 32 & 0 \\
& $02: 50: 15$ & & & \\
$\begin{array}{c}\text { Sentinel } \\
-2 \mathrm{~A}\end{array}$ & $\begin{array}{c}20170429 \\
02: 46: 03\end{array}$ & 3 & 23 & 0 \\
$\begin{array}{c}\text { Landsat } \\
8\end{array}$ & $\begin{array}{c}20170402 \\
02: 26: 10\end{array}$ & 3 & 20 & 0 \\
\hline
\end{tabular}

Table 1. Meteorological data around the Sentinel 2A image time and the second Landsat8 image time.

Source: NOAA's National Climatic Data Center

(https://gis.ncdc.noaa.gov/maps/ncei/cdo/hourly);

China Meteorological Data Network

(http://www.nmic.cn/site/article/id/29086.html)

In this study, the preprocessing of two different remote sensing images is atmospheric correction. The Landsat8 images (2016 and 2017) were calibrated by radiation first, and then the atmospheric correction of the images was preprocessed by 
FLAASH model. Since the product level of Sentinel-2A image is $1 \mathrm{C}$, although the $1 \mathrm{C}$ data have been corrected by orthorectification and Top Of Atmosphere (TOA) reflection processing, there are still some defects in spectral characteristics and ground deformation transformation, so the $1 \mathrm{C}$ data downloaded directly need to be further processed. This paper deals with Sentinel-2A images directly using Sen2cor provided by ESA. Sen2cor is a prototype processor, which performs atmospheric, topographic and cirrus correction tasks of $1 \mathrm{C}$ input data and automatically generates L2A-level data. The L2A level data processing is based on LUT, which uses the aerosol optical thickness, reflectance and phase function under different complex atmospheric conditions to correct the atmospheric underlying surface emissivity. The effect of atmosphere on remote sensing data is considered to the greatest extent (i.e. precise atmospheric correction). Therefore, Sentinel-2A data processing is to explore L2A level data. In order to ensure the accuracy of the calculation of each index and remote sensing ecological index, it is necessary to tailor the data carefully. Because the humidity component in RSEI model is related to vegetation and soil moisture, if there are large areas of water in the study area, the proportion of water will increase, which will lead to the inaccuracy of the calculated humidity index. Therefore, before calculating the model, the water body in the study area must be masked. The improved normalized water index MNDWI was used to extract water in this paper. MNDWI is the modified normalized difference water index (Xu, 2005), expressed as(1). At the same time, the 2016 Landsat8 image has a little thick cloud. This paper uses the cloud and cloud shadow matching algorithm Fmask to quickly and accurately identify the cloud and cloud shadow areas and mask.

$$
M N D W I=\frac{B 3-B 6}{B 3+B 6}
$$

Where B2, B3, and B6 denote a blue band, a green band and a mid-infrared band (1520-1700nm) respectively.

According to Pingtan County administrative division map, remote sensing images are clipped, waters in the clipped images are masked, and a small amount of cloud masks in Landsat 8 in 2016 are processed. The results of the pretreatment are shown in Figure 2 (a) (d):

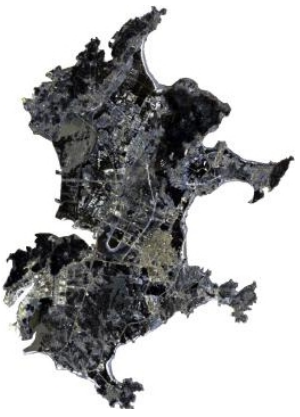

(a)

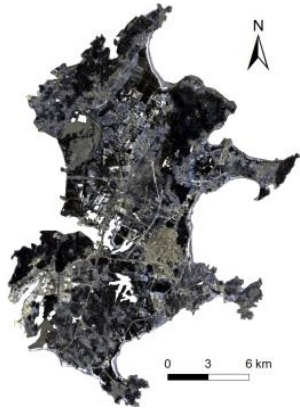

(b)

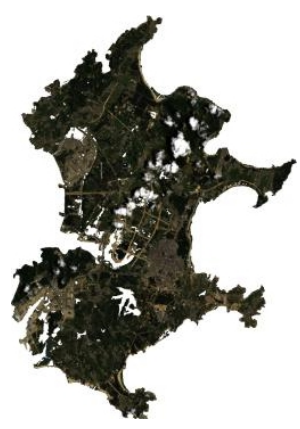

(c)

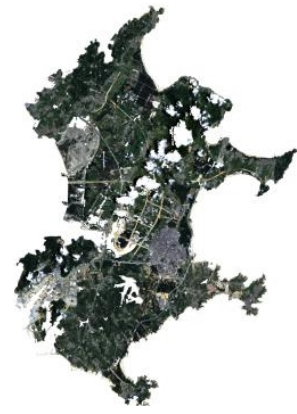

(d)
Figure 2. Water mask and cloud mask. (a)(b)show the image before water mask and the image after water mask, (c)(d) show the image before thick cloud maskand image after thick cloud mask.

\subsection{Establishment of Remote Sensing Ecological Index (RSEI)}

RSEI model is a widely used means of ecological monitoring and assessment. Its index values are directly calculated from different bands of remote sensing images, and do not rely on other ground reference data. The model is simple and convenient, and can be applied to a wide range of scales, such as the cities or nature reserves. Therefore, in this paper, we adopt a new ecological evaluation index which base on remote sensing information (Xu, 2013). The index model is composed of four indicators: vegetation index (NDVI), humidity index (Wet), dryness index (NDSI), and heat index (LST). These four indicators are closely related to human beings and ecosystems, and can comprehensively analyze and evaluate ecosystems. Four indices are calculated, then the four indices are combined into a numerical value by principal component analysis to judge the ecological environment quality. Accordingly, RSEI is a function of the four indicators, the formula is shown as (2)

$$
R S E I=f\{N D V I, \text { Wet }, N D S I, L S T\}
$$

NDVI was first proposed by RouseJ.W. based on the biophysical mechanism of vegetation(RouseJ.W., 1973). The solar spectrum is strongly absorbed by chlorophyll in red light band, and strongly reflected by leaf cell structure in near infrared band. NDVI is the most widely used vegetation index, which is applied in monitoring plant growth and ecological environment. vegetation index formula is expressed as equation (3).

$$
N D V I=\frac{B 4-B 5}{B 4+B 5}
$$

Where B4 and B5 denote a red band, a near-infrared band respectively.

Moisture index can be transformed into humidity component. The humidity component reflects the humidity 
status of the surface soil and vegetation. Soil moisture plays a key role in the process of water exchange between the atmosphere and the surface. Humidity is also an important index to reveal land degradation. The wetness component of the Landsat 8 can be computed with the formula (4) (Baig et al., 2014), the wetness component of the Sentinel-2A can be computed using the following equation (5) (Roumen Nedkov., 2017).

$$
\begin{aligned}
W \text { et }= & 0.1511 \mathrm{~B} 2+0.1973 B 3+0.3283 B 4 \\
& +0.3407 B 5-0.7117 B 6-0.4559 B 7
\end{aligned}
$$

$$
\begin{aligned}
& \text { Wet }=0.0649 B 1+0.1363 B 2+0.2802 B 3 \\
& +0.3072 B 4+0.5288 B 5+0.1379 B 6-0.0001 B 7 \\
& -0.0807 B 8-0.1389 B 8 A-0.0302 B 9+0.0003 B 10 \\
& -0.4064 B 11-0.5602 B 12
\end{aligned}
$$

For formula (4), where B2 to B7 are the corresponding bands of the Landsat8 image. For formula (5), B1 to B12 are the corresponding bands of the Sentinel-2A image, respectively.

Due to the lack of thermal infrared band of Sentinel-2A imagery, the land surface temperature (LST) of the study area was obtained from the Landsat 8 TIRS image. For LST, this paper uses Wang et al. proposed an improved Mono-Window (IMW) algorithm based on the 10th band of Landsat 8 (Wang F., 2015). The basic expression of the algorithm is shown in formula (6), (7), (8).

$$
\begin{aligned}
& T_{s}=\left[a_{10}\left(1-C_{10}-D_{10}\right)+\left(b_{10}\left(1-C_{10}-D_{10}\right)\right.\right. \\
& \left.\left.+C_{10}+D_{10}\right) T_{\text {sensor }}-D_{10} T_{a}\right] / C_{10}
\end{aligned}
$$

$$
C_{10}=\tau_{10} \varepsilon_{10}
$$

$$
D_{10}=\left(1-\tau_{10}\right)\left[1+\left(1-\varepsilon_{10}\right) \tau_{10}\right]
$$

Where Ts is the LST retrieved from the Landsat 8 TIRS Band 10 data; $T_{\text {SENSOR }}$ represents the luminance temperature value in the thermal infrared band, $T_{a}$ represents the mean atmospheric temperature; $\tau$ is atmospheric transmittance of Landsat 8 TIRS Band $10 ; \varepsilon$ is the ground emissivity for the band; $a$ and $b$ are the constants used to approximate the derivative of the Planck radiance function for the TIRS Band 10 , between 0 and $50{ }^{\circ} \mathrm{C}$, $\mathrm{a}$ and $\mathrm{b}$ select $-62.7182,0.4339$.

In this paper, the building index (IBI) and the bare soil index (BI) work together to represent dryness NDSI (Xu H Q., 2011; Jimenez-Munoz J C., 2015). The IBI index can effectively block background noise and significantly enhancing building land characteristics. Because the study area has a large bare land area, the building and the bare soil work together to form a dry, so the dryness index (NDSI) is synthesized by both IBI and BI. The calculation formulas are as follows (9), (10), (11) Shown.

$$
\begin{aligned}
& I B I=\{2 B 6 /(B 6+B 5)-[B 5 /(B 5+B 4)+B 3 /(B 3+B 6)]\} / \\
& \{2 B 6 /(B 6+B 5)+[B 5 /(B 5+B 4)+B 3 /(B 3+B 6)]\}
\end{aligned}
$$

$$
\begin{aligned}
& B I=[(B 6+B 4)-(B 5+B 2)] / \\
& {[(B 6+B 4)+(B 5+B 2)]}
\end{aligned}
$$

$$
N D S I=(I B I+B I) / 2
$$

Where $\mathrm{B} 2$ to $\mathrm{B} 6$ are the corresponding bands of the Landsat 8 image.

After calculating the four indicators of NDVI, Wet, NDSI, and LST, the dimensions of the four indices are different. Each indicator should be normalized so that the four values are mapped between 0 and 1 . The formula is shown in equation (12)

$$
I_{\text {Norm }}=\left(I_{i}-I_{\min }\right) /\left(I_{\max }-I_{\min }\right)
$$

In the formula, $I_{\text {Norm }}$ represents the normalized value of an indicator, $I_{i}$ represents the value of a certain indicator in the pixel i, $I_{\max }$ represents the maximum value of the indicator, and $I_{\text {min }}$ represents the minimum value of the indicator.

After obtaining four index components, the principal component transformation is used to generate the RSEI index. The main advantage of using principal component analysis is that the weight of each indicator is not determined manually, but is determined automatically and objectively based on the contribution of each index to the first principal component (PCI). The transformation of the principal component can be calculated by the PCA analysis of the ArcGIS spatial analyst tools. The first component of the output is the initial remote sensing ecological index RSEI $I_{\mathrm{PCI}}$, as shown in equation (13), Because this component usually accounts for more than $80 \%$ of the total variable (table2). In order to facilitate index

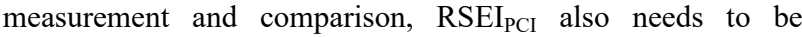
normalized. Due to the calculated RSEI value, the high value shows the ecological difference, the low value shows the ecological good. In order to let higher values represent more ecologically robust conditions as usually expected, the RSEI was subtracted from 1 . The normalization formula is as shown in equation (14), and then the RSEI index is output. The value is between 0 and 1 , the closer to 1 , the better the ecological environment quality. This method does not require human intervention to confirm the right, easy to understand, and can compare the multi-year time series. 


$$
\begin{gathered}
R S E I_{P C 1}=P C 1 f\{N D V I, \text { Wet }, N D S I, L S T\} \\
R S E I=\left(R S E I_{P C 1}-R S E I_{P C 1 \_\min }\right) / \\
\left(R S E I_{P C 1 \_\max }-R S E I_{P C 1 \_ \text {min }}\right)
\end{gathered}
$$

\subsection{Main experimental steps}

(1) Image preprocessing: The Landsat8 radiation calibration is used to obtain the original image data $\mathrm{DN}$ value, and the image surface reflectivity is calculated by the corresponding calibration formula to reduce the atmospheric error and the inherent error. The image was atmospherically

corrected using the ENVI Atmospheric Correction Tool (FLAASH) and Tropical was selected as the atmospheric model parameter. The Sentinel-2A data is directly preprocessed with Sen2cor provided by ESA. The water mask, cloud and shadow mask are applied to the image of the study area after the atmospheric correction.

(2) Calculate the remote sensing ecological index: Calculating the ecological index of the pre-processed remote sensing image band, obtain the four ecological indicators of the two Landsat8 images and the two Sentinel-2A images, then normalizethe four ecological indicators, calculate PCI, and finally obtain the RSEI images of each phase andthe model results are compared and analyzed.

(3) Using the multi-source data of the same period, such as GF-2, Google Earth History Image, etc. The results are analyzed and discussed through visual interpretation.

\section{RESULTS AND ANALYSIS}

\subsection{RSEI index time and space change analysis}

As shown in Figure 3 (a, b, c, d), they are Sentinel-2A and Landsat 8 remote sensing ecological index images $(2016,2017)$. From Figure 3 (a corresponds to b, c corresponds to d), in 2016, Landsat 8 and Sentinel-2A remote sensing ecological index images have good ecological quality, and the ecological status distribution was similar. In 2017, the Landsat 8 and Sentinel-2A remote sensing ecological index images showed poor ecological quality, and the ecological status distribution was similar. From 2016 to 2017, Figure 3 (a corresponds to c, b corresponds to $\mathrm{d}$ ), and the range of image changes of the two Landsat 8 remote sensing ecological indices is the same as that of the two Sentinel-2A remote sensing ecological indices. The image of 2016 is from the end of June to July, when the crop growth period is at this time, so the vegetation index value is higher and the ecological quality is better in 2016. However, the image for 2017 is in April, at which time it is mainly dominated by bare soil, NDSI indicator is high, which is the main reason for the downward trend of the two RSEIs in 2017.

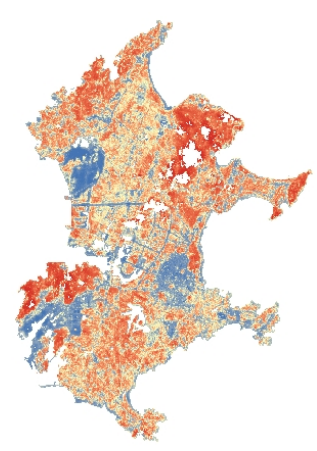

(a)

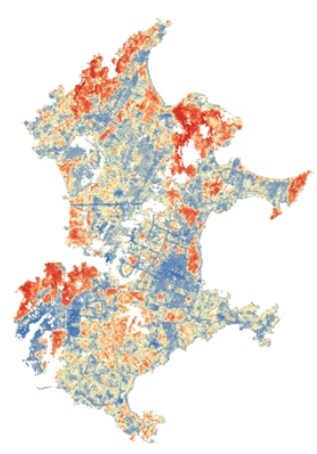

(c)

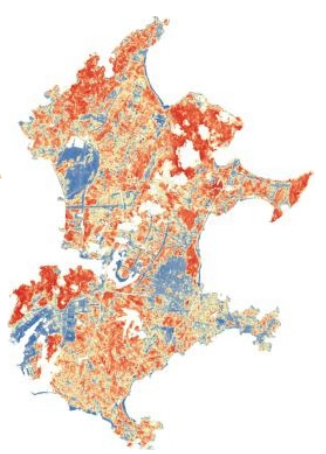

(b)

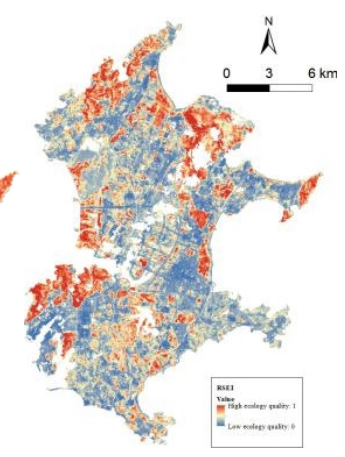

(d)

Figure 3. Four RSEI images. (a) (b) show the RSEI values of Sentinel-2A and Landsat8 in 2016, (c) (d) show the RSEI values of Sentinel-2A and Landsat 8 in 2017.

Table 2 is the PC1 data of the four RSEI images normalized values of the four indicators and the mean RSEI of the Pingtan. Combined with Figure 4, it can be clearly seen that from 2016 to 2017, the ecological quality of remote sensing obtained by Landsat 8 and Sentinel-2A is a downward trend. As seen in Table 3 , the interpretability of the first principal component of PCI is about $80 \%$, indicating that the PCI extraction results are better. From the average index of RSEI, both show a downward trend. the mean value of Landsat 8 RSEI was 0.56 in 2016, and was 0.47 in 2017 , a decrease of $16 \%$. The mean value of Sentinel-2A RSEI was 0.60 in 2016, and was 0.54 in 2017 , a decrease of $12 \%$. The reason for the smaller decline in sentinel assessment results is that the weight of the NDVI of the two is different in 2017. The NDVI weighting factor of Landsat 8 is 0.486 , and the sentinel-2A is 0.600 . By analyzing statistics related to RSEI images of Sentinel-2A and Landsat 8, the reason for the decrease in RSEI is that the NDSI value increases, and the sum of the heat and dryness index weights which have negative effects on ecology is greater than the greenness and humidity index which have positive effects on ecology. Further observations revealed that although the value of NDVI in the study area increased, the increase in the exposed surface and the increase in a small amount of construction land in 2017, the value of NDSI and the weight coefficient increased, resulting in a downward trend in the overall assessment index. The increase in the NDSI weighting factor also indicates that the impact of urban expansion on the environment is more pronounced. 
The International Archives of the Photogrammetry, Remote Sensing and Spatial Information Sciences, Volume XLII-3/W10, 2020 International Conference on Geomatics in the Big Data Era (ICGBD), 15-17 November 2019, Guilin, Guangxi, China

\begin{tabular}{|c|c|c|c|c|c|c|c|c|}
\hline & \multicolumn{2}{|c|}{$06-23-2016$} & \multicolumn{2}{|c|}{$07-20-2016$} & \multicolumn{2}{|c|}{$04-29-2017$} & \multicolumn{2}{|c|}{$04-02-2017$} \\
\hline & \multicolumn{2}{|c|}{ Sentinel-2A } & \multicolumn{2}{|c|}{ Landsat 8} & \multicolumn{2}{|c|}{ Sentinel-2A } & \multicolumn{2}{|c|}{ Landsat8 } \\
\hline & Mean & PCI & Mean & PCI & Mean & PCI & Mean & PCI \\
\hline NDVI & 0.684 & 0.765 & 0.636 & 0.703 & 0.722 & 0.600 & 0.693 & 0.486 \\
\hline Wet & 0.544 & 0.104 & 0.645 & 0.319 & 0.504 & 0.101 & 0.604 & 0.247 \\
\hline NDSI & 0.443 & -0.452 & 0.487 & -0.516 & 0.553 & -0.678 & 0.569 & -0.684 \\
\hline LST & 0.496 & -0.444 & 0.496 & -0.369 & 0.479 & -0.417 & 0.479 & -0.483 \\
\hline $\begin{array}{l}\text { Percent of Eigen } \\
\text { Values }(\%)\end{array}$ & \multicolumn{2}{|c|}{79.608} & \multicolumn{2}{|c|}{81.149} & \multicolumn{2}{|c|}{80.109} & \multicolumn{2}{|c|}{80.232} \\
\hline RSEI & \multicolumn{2}{|c|}{0.60} & \multicolumn{2}{|c|}{0.56} & \multicolumn{2}{|c|}{0.54} & \multicolumn{2}{|c|}{0.47} \\
\hline
\end{tabular}

Table 2. The PC1 data of the four RSEI images、 normalized values of the four indicators and the mean RSEI of the Pingtan

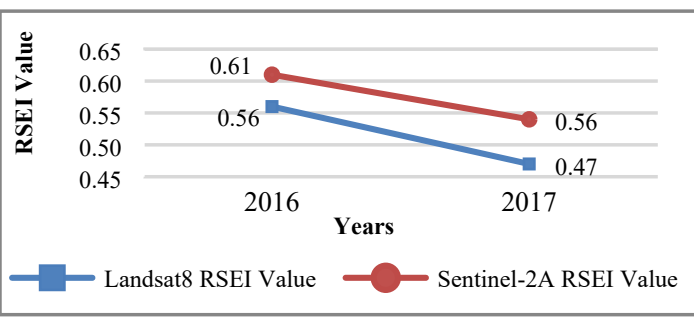

Figure 4. RSEI values for Landsat8 and Sentinel-2A

\subsection{RSEI ecological classification analysis}

In order to quantitatively and visually analyze the ecological environment of the study areabased on the RSEI images obtained from the two remote sensing image data, this paper will grade the RSEI images. The RSEI interval is divided into five levels, from low to high, respectively, level 1, level 2, level 3, level 4, Level 5. The statistical data table of the temporal and spatial changes of the ecological environment in the study area shown in Table 3, and the visual analysis chart shown in Figure 5. The following characteristics are shown in the figure and in the table:

(1)Overall, comparing the RSEI image levels of Landsat8 and Sentinel-2A in the same year, the trend of each level is the same.

(2)From 2016 to 2017, the change trend of graded area of two Landsat8 RSEI images is the same as that of two Sentinel-2A RSEI images. In 2016In 2016, it was dominated by grades 3 and 4, and in 2017, it was dominated by grades 2 and 3 .

(3) From the perspective of space, both Landsat8 RSEI image and Sentinel-2A RSEI image show that the high ecological environment quality of the study area is concentrated in the area with high vegetation coverage, while the poorecological environment quality is distributed in the old city area and new urban construction area. The images obtained in 2016 were from the end of June to July, when it was in the crop growth period. Therefore, the vegetation index values in the central and northern farmland areas of the study area are better, and the RSEI levels are concentrated at level 3 and level4. However, The images obtained in 2016 were April, when the central and northern regions are dominated by bare soil, and the ecological quality is poor, and the RSEI levelsare concentrated at level 2 and level 3.

Table 3. Area Statistics of RSEI level

\begin{tabular}{|c|c|c|c|c|c|c|c|c|}
\hline \multirow{3}{*}{ RSEI level } & \multicolumn{2}{|c|}{$06-23-2016$} & \multicolumn{2}{|c|}{$07-20-2016$} & \multicolumn{2}{|c|}{$04-29-2017$} & \multicolumn{2}{|c|}{ 04-02-2017 } \\
\hline & \multicolumn{2}{|c|}{ Sentinel-2A } & \multicolumn{2}{|c|}{ Landsat 8} & \multicolumn{2}{|c|}{ Sentinel-2A } & \multicolumn{2}{|c|}{ Landsat 8} \\
\hline & $\begin{array}{c}\text { AREA/k } \\
\text { m2 }\end{array}$ & $\begin{array}{c}\text { Percentage } \\
(\%)\end{array}$ & AREA/km2 & $\begin{array}{c}\text { Percentage } \\
(\%)\end{array}$ & AREA/km2 & $\begin{array}{c}\text { Percentage } \\
(\%)\end{array}$ & AREA/km2 & $\begin{array}{c}\text { Percentage } \\
(\%)\end{array}$ \\
\hline $1(0.0-0.2)$ & 0.220 & 0.08 & 6.426 & 2.46 & 0.106 & 0.00 & 5.060 & 1.95 \\
\hline $2(0.2-0.4)$ & 49.279 & 19.00 & 55.704 & 21.36 & 56.863 & 4.18 & 115.429 & 44.46 \\
\hline $3(0.4-0.5)$ & 63.233 & 24.38 & 68.327 & 26.19 & 109.425 & 51.50 & 76.455 & 29.45 \\
\hline $4(0.6-0.8)$ & 109.662 & 42.28 & 97.397 & 37.34 & 73.127 & 33.74 & 49.811 & 19.18 \\
\hline $5(0.8-1.0)$ & 37.000 & 14.26 & 32.996 & 12.65 & 19.470 & 10.58 & 12.890 & 4.96 \\
\hline
\end{tabular}


(a)

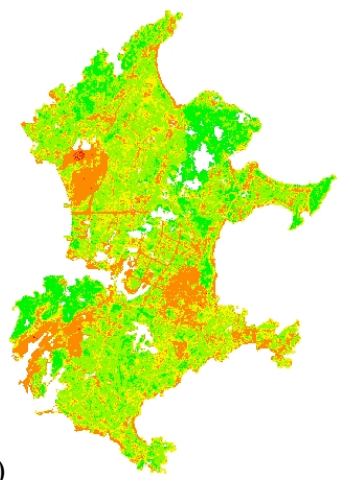

(b)

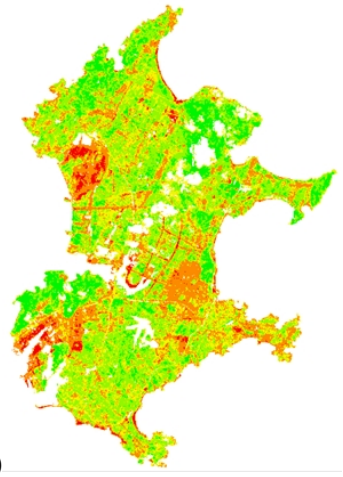

(c)

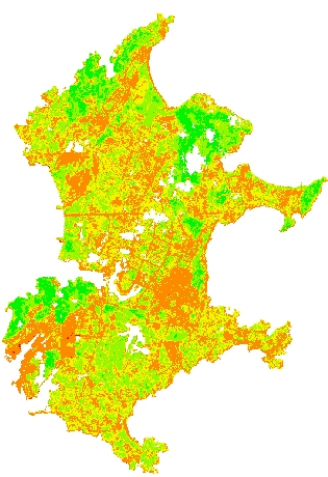

(d)

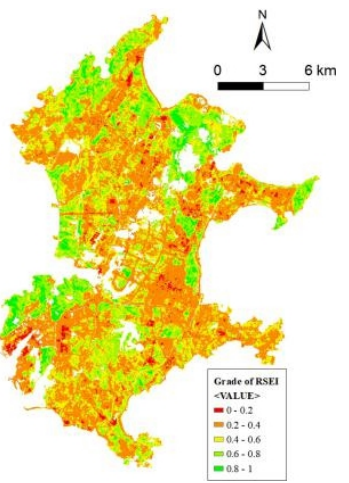

Figure 5. Four RSEI images classification statistics. (a)(b) shows the regional statistics of 5 RSEI levels of Sentinel-2A and Landsat8 in 2016, (c)(d) shows the regional statistics of 5 RSEI levels of Sentinel-2A and Landsat8 in 2017.

\subsection{Local comparison analysis}

As shown in Figure 6, four typical local regions A, B, C, and $\mathrm{D}$ are intercepted from the two-year RSEI image of Sentinel-2A. In 2016, the increase in NDVI was mainly due to the increase in vegetation in farmland areas caused by seasonal changes (A, D). In 2017, the main reason for the increase in NDSI was the increase in bare areas in the farmland area, and the addition of new construction land in the northern part of the island's water source (C). It can also be clearly seen from the figure that the Sentinel-2A image has a higher resolution, can more clearly classify the land, significantly improve the spatial details of the RSEI, and obtain a more accurate ecological quality assessment.

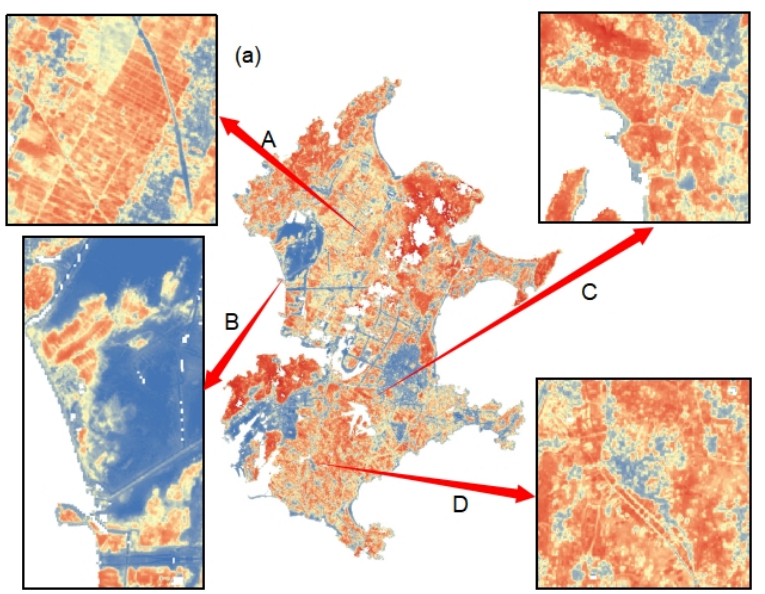

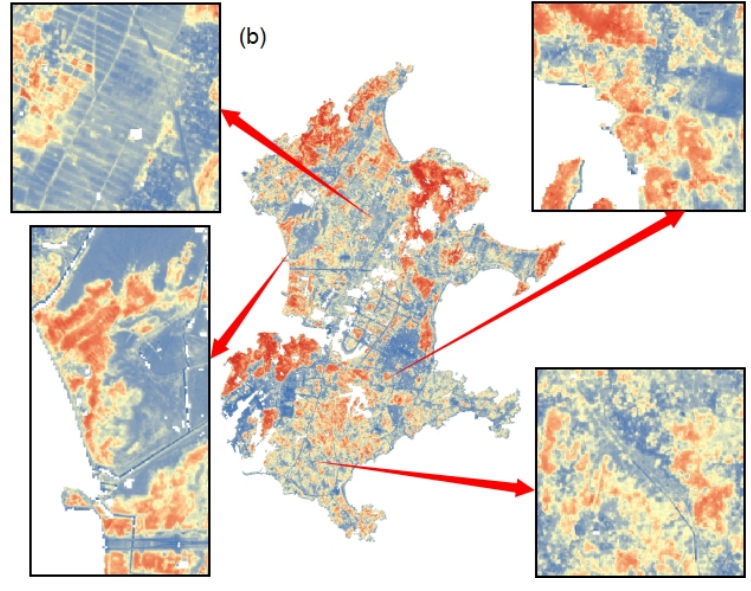

Figure 6. Local comparison analysis of Landsat 8 and Sentinel-2A RSEI image. (a)(b) show the local RSEI images of Sentinel-2A and Landsat8 in 2016

\subsection{Comparison of RSEI values of each township obtained by Landsat8 and Sentinel-2A}

According to the administrative plan of the study area, there are 11 towns in the study area. The ArcGIS spatial analysis tool is used to calculate the RSEI values of each township, and further refine the comparability of Landsat 8 and Sentinel-2A. As seen from Figure 7, in the same year, each township RSEI value obtained from the Landsat8 image is almost the same as the RSEI value of each township obtained by the Sentinel-2A image, and the increase or decrease trend is the same.In the same town, the two RSEI values change very little, around $4 \%$ in 2016 and around $10 \%$ in 2017. It shows that Sentinel-2A and Landsat8 can complement each other to complete the assessment of ecological environment quality. 

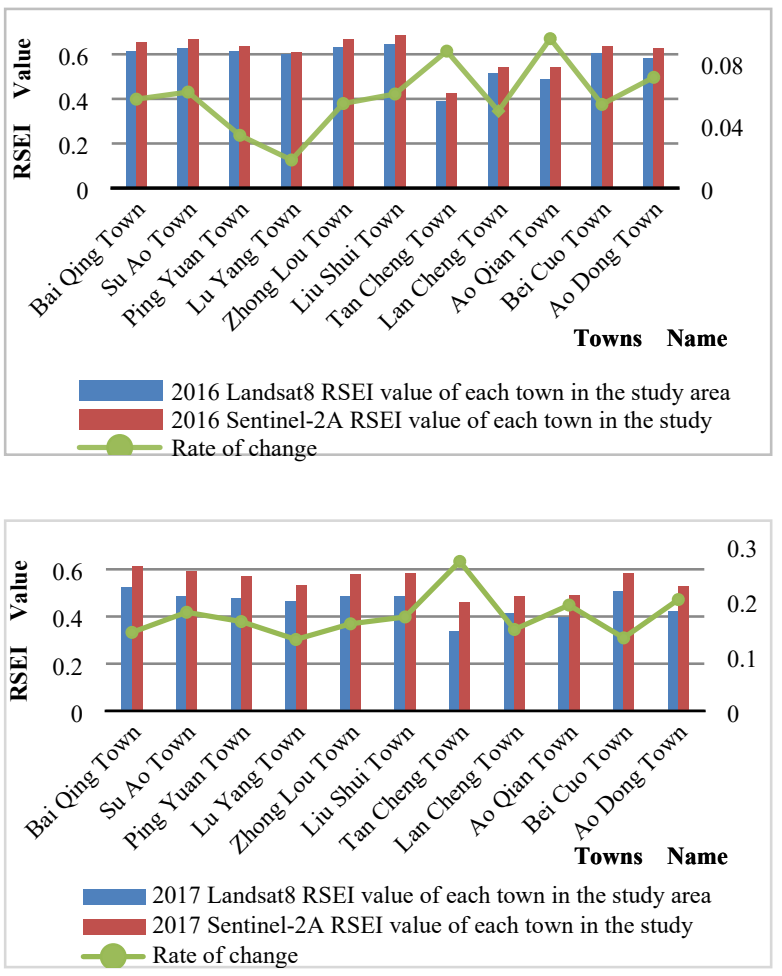

Figure 7. Variation of RSEI at each towns

Further combined with two GF-2 images and Google Earth historical images provided by the Ministry of Land and Environment of Pingtan County, the high-resolution images and the RSEI images were compared and analyzed. The analysis results show that the Sentinel-2A image has higher resolution, can more clearly classify the land, significantly improve the spatial details of the RSEI, and obtain a more accurate ecological quality assessment. In addition, Figure 8 (a and $b$ ) in the central part of the study area is dominated by farmland areas. Figure 8 (c and d) in the northern part is mainly scattered villages, with farmland distributed around it. The image obtained in 2016 is in the plant growth period. Therefore, the ecological quality of the central and northern regions of the study area has been greatly improved, indicating that seasonal changes in vegetation growth will affect the RSEI indicator assessment. In the north of the 36-foot lake, Figure 8 (e and $\mathrm{f}$ ), due to the expansion of the city center, there are a small amount of agricultural land in the study area, and the unused land is converted into construction land. The ecological quality of newly-added construction land has decreased in recent years; Figure 8 ( $g$ and $h$ ) of the reclamation area, the vegetation increased a little, and the relevant government departments actively solved the problems of land reclamation and forest use, which further increased the vegetation coverage of the area. In 2017, the ecological quality of this area increased slightly.
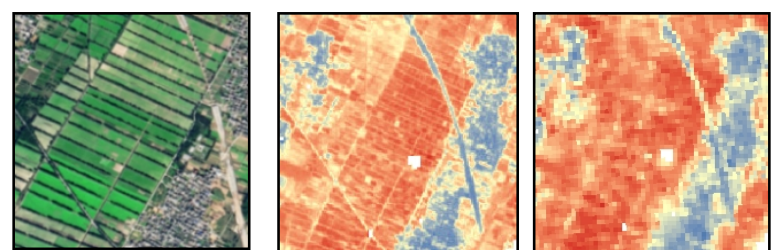

(a)
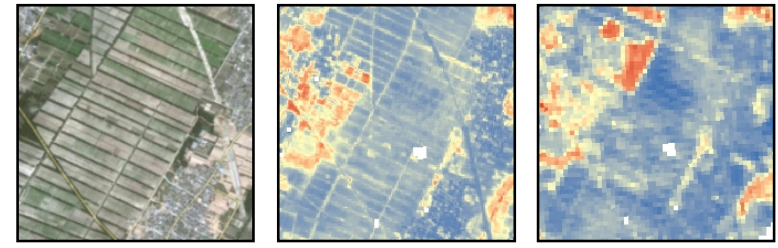

(b)
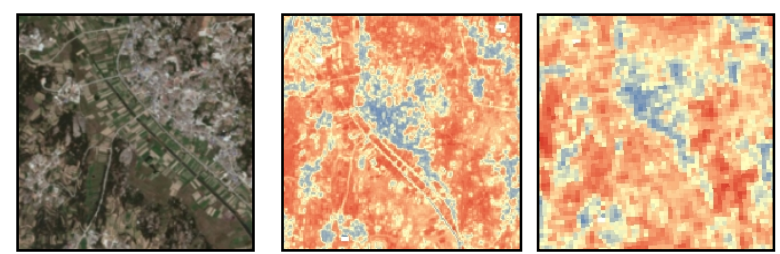

(c)
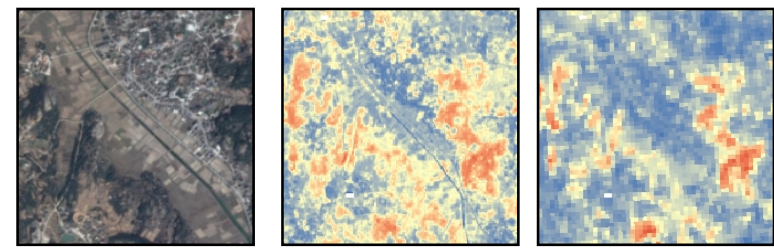

(d)
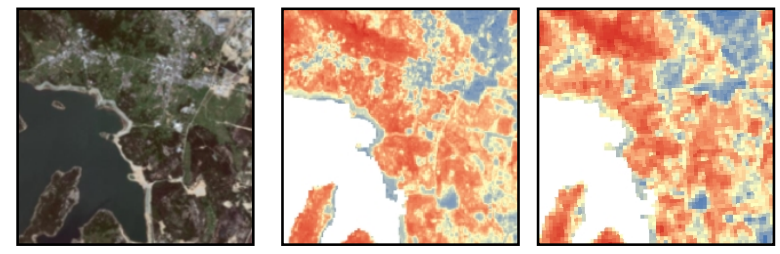

(e)
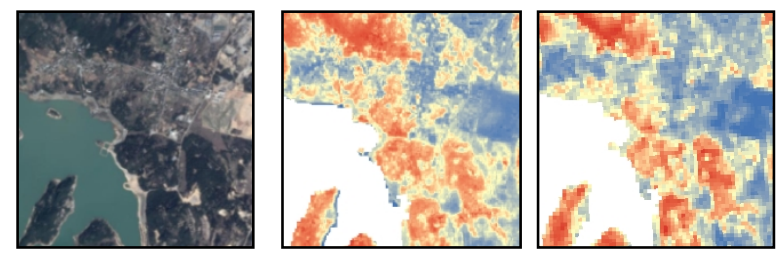

(f)
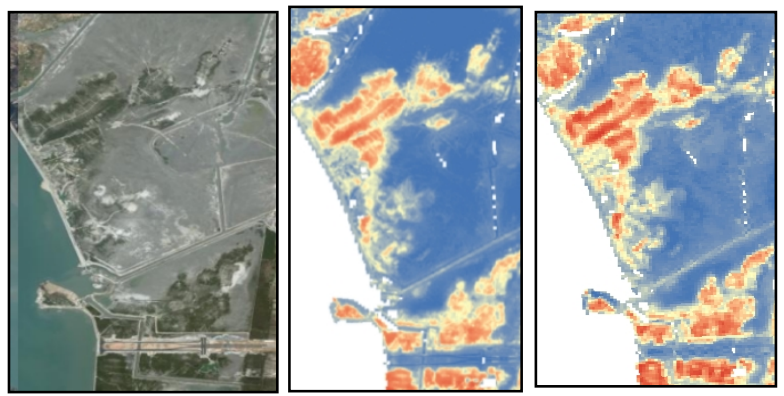

(g) 

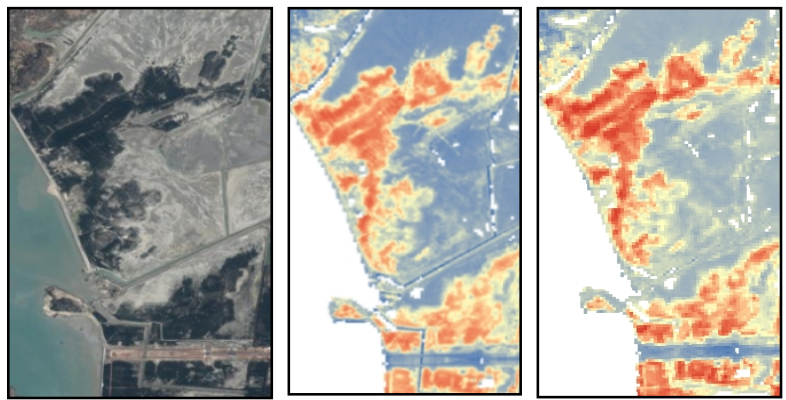

(h)

Figure 8. Visual verification of GF-2 images and Google Earth historical images $(2016,2017)$. (a)(b) A screenshot showing the central farmland area in the GF-2 image and a corresponding screenshot of the RSEI image of Sentinel-2A and Landsat8. (c)(d) showing a screenshot of the northern farmland area in the Google Earth historical image and corresponding Screenshots of RSEI images of Sentinel-2A and Landsat8.(e)(f) Screenshots of the water source area of the Google Earth Historical Image Research Area and corresponding screenshots of the RSEI images of Sentinel-2A and Landsat8. (g)(h) shows a screenshot of the returning farmland to forest area in Google Earth's historical image and a corresponding screenshot of the RSEI image of Sentinel-2A and Landsat8.

\section{CONCUSIONS}

This paper discusses how to use the Landsat8 and Sentinel-2A remote sensing data to obtain the ecological index RSEI, and directly use the RSEI to assess the quality of the ecological environment. The similarities and differences of the RSEI images obtained from the two remote sensing data were analyzed.

This study shows that both Sentinel-2A data and landsat8 data can be directly used to characterize regional ecological quality using the RSEI model. The RSEI images obtained from the two different remote sensing images have the same ground object representation, and the RSEI values of all regions in the study area have the same trend. The RSEI indicator is combined with four ecological indicators, and the calculation method is simple and suitable for rapid evaluation. This method does not require human intervention to confirm, easy to understand, not only to quantify indicators, visualize results, and facilitate decision-making deployment. From 2016 to 2017, the results of two remote sensing data show that the ecological quality of the region is susceptible to crop phenology, because the vegetation in the region is dominated by farmland. There are still more agricultural land and unused land in the study area, which also indicates that in the future development and planning of the new district, due to the protection of the ecological environment, the conversion of agricultural land to construction land should be minimized. At the same time, the ecological quality of new construction land adjacent to the northern part of the island's water source has declined in recent years, and it is necessary to strengthen monitoring of changes in this area.

However, from the practical application, we also found that we need to pay attention to some issues. For the Landsat 8 data source, the resolution is only 30 meters, which is not suitable for small-scale refinement evaluation of counties and cities.Sentinel-2A has high data resolution and strong revisiting capability, and is widely used in ground monitoring. It has a great role in vegetation extraction and biomass estimation, and its application potential is huge. Through the comparative analysis of Landsat 8 and Sentinel-2A remote sensing data in ecological quality assessment, Sentinel-2A images have higher resolution, can more clearly classify the land, significantly improve the spatial details of RSEI, and obtain a more accurate ecology. Due to the lack of thermal infrared band in Sentinel-2A data, it is necessary to calculate the thermal factor in the RSEI model using the thermal infrared band of Landsat 8 with the same imaging time, which reduces the ecological quality assessment directly using Sentinel-2A remote sensing.

\section{ACKNOWLEDGEMENTS}

This research was supported by Nature Science Foundation of Fujian Province of China (Grant No. 2017J10469).

\section{REFERENCES}

Hong-Yi, L. I., Shi, Z., Guo, Y. D., \& Sha, J. M., 2006: Evaluation of ecological environment quality in fujian province based on remote sensing and gis techniques. Remote Sensing Technology \& Application, 21(1), 49-54.

Robert E Kennedy., Serge Andréfouët., Warren B Cohen., Cristina Gómez., Patrick Griffiths., Martin Hais., Sean P Healey., Eileen H Helmer., Patrick Hostert., Mitchell B Lyons., Garrett W Meigs., Dirk Pflugmacher., Stuart R Phinn., Scott L Powell., Peter Scarth., Susmita Sen., Todd A Schroeder., Annemarie Schneider., Ruth Sonnenschein., James E Vogelmann., Michael A Wulder., Zhe Zhu., 2014: Bringing an ecological view of change to landsat-based remotesensing. Frontiers in Ecology and the Environment, 12(6), 339-346.

Ochoa-Gaona, S., Kampichler, C., Jong, B. H. J. D., S. Hernández., Geissen., V.,\&Huerta, E.,2010: A multi-criterion index for the evaluation of local tropical forest conditions in mexico. Forest Ecology and Management, 260(5), 0-627.

Yuan, F., \& Bauer, M. E., 2007: Comparison of impervious surface area and normalized difference vegetation index as indicators of surface urban heat island effects in landsat imagery. Remote Sensing of Environment, 106(3), 375-386.

Nichol, \& Janet.,2009: An emissivity modulation method for spatial enhancement of thermal satellite images in urban heat island analysis. Photogrammetric Engineering \& Remote Sensing, 75(5), 547-556.

Xu, H., Hu, X., \& Guan, H., 2017: Development of a fine-scale discomfort index map and its application in measuring living environments using remotely-sensed thermal infrared imagery. Energy and Buildings, S0378778817307946.

Wan B T., Wang W J., Cui S H., 2009: Evaluation method of urban ecological environment quality [J]. Journal of Ecology, 2009, 29 (03): 1068-1073. 
Han-Qiu, X. U., 2013: A remote sensing index for assessment of regional ecological changes. China Environmental Science,33(5), 889-897.

Lakes, T., \&Kim, H. O., 2012: The urban environmental indicator "biotope area ratio" - an enhanced approach to assess and manage the urban ecosystem services using high resolution remote-sensing. Ecological Indicators, 13(1), 0-103.

Li, J., Roy, D.P., 2017: A global analysis of sentinel-2A, sentinel-2B and Landsat- 8 data revisit intervals and implications for terrestrial monitoring. Remote Sens. 9 (9), 902.

Han-Qiu, X. U. 2005: A study on information extraction of water body with the modified normalized difference water index (mndwi). Journal of Remote Sensing, 9(5), 589-595.

Xu H Q.,2013: A remote sensing urban ecological index and itsapplication[J]. Acta Ecologica Sinica, 2013,33(24):7853-7862.

Rouse Jr, J., Haas, R. H., Schell, J. A., \& Deering, D. W., 1974: Monitoring vegetation systems in the Great Plains with ERTS. In: Conference Proceedings of the Third ERTS Symposium, NASA SP-351, Washington D.C., pp. 309-317.

Baig, M. H. A., Zhang, L., Shuai, T., \& Tong, Q. 2014: Derivation of a tasselled cap transformation based on Landsat 8 at-satellite reflectance. Remote Sensing Letters, 5(5), 423-431.

Nedkov R., 2017: Orthogonal transformation of segmented images from the satellite Sentinel-2[J]. Comptes rendus de l'Academie bulgare des Sciences, 70(5): 687-692.

Wang, F., Qin, Z., Song, C., Tu, L., Karnieli, A., \& Zhao, S. 2015: An improved mono-window algorithm for land surface temperature retrieval from Landsat 8 thermal infrared sensor data. Remote Sensing, 7(4), 4268-4289.

Xu H Q., 2011: A New Index-based Remote Sensing Index for Building Land and Its Eco-environmental Significance [J]. Remote Sensing Technology and Applications, Issue (3).

Jiménez-Muñoz, J. C., Sobrino, J. A., Skoković, D., Mattar, C., \& Cristóbal, J., 2014: Land surface temperature retrieval methods from Landsat-8 thermal infrared sensor data. IEEE Geoscience and remote sensing letters, 11(10), 1840-1843. 